\title{
Investigation of Class I Integron in Salmonella infantis and Its Association With Drug Resistance
}

\author{
Fariba Asgharpour ${ }^{1}$; Ramazan Rajabnia ${ }^{2}$; Elaheh Ferdosi Shahandashti ${ }^{3}$; Mahmood Amin \\ Marashi ${ }^{4}$; Mahya Khalilian ${ }^{5}$; Zahra Moulana ${ }^{2, *}$ \\ ${ }^{1}$ Department of Microbiology,paramedical Sciences,Babol University of Medical Sciences,Babol, IR Iran \\ ${ }^{2}$ Infectious Diseases Research Center, Babol University of Medical Sciences, Babol, IR Iran \\ 3 Department of Microbiology \& Immunology, Faculty of Medicine, Babol University of Medical Sciences, Babol, IR Iran \\ ${ }^{4}$ Department of Microbiology and Immunology, Alborz University of Medical Sciences, Karaj, IR Iran \\ 5 Department of Microbiology and Immunology, Alborz University of Medical Sciences, \\ *Corresponding author: Zahra Moulana, Infection Diseases Research Center, Babol University of Medical Sciences, Babol, IR Iran. Tel: +98-1113268528; +98-9113130045, Fax: +98- \\ 1113234367, E-mail:zmoulana@yahoo.com
}

Received: January 19, 2013; Revised: April 24, 2013; Accepted: June 1, 2013

Background: Infection with non-typhoid Salmonella(NTS) is one of the most important health problems all over the world. Antimicrobial drug resistance is increasing among Salmonella infantis species.

Objectives: The aim of this study was to investigate the frequency of presence of class 1 integrons in S. infantis species as well as its association with drug resistance.

Materials and Methods: This cross-sectional study was performed on $50 \mathrm{~S}$. infantis isolated strains, collected from chicken samples between 2009-2011. These strains were identified by standard biochemical tests and serology. Antibiotic susceptibility profiles and minimum inhibitory concentration determination for 14 antibacterial agents were performed using micro dilution and disk diffusion methods. The detection of class 1 integron was performed by the PCR method. The demographic and microbiological data for the integron positive and negative isolates were compared by SPSS software.

Results: Eighteen out of $50(36 \%)$ of isolated S. infantis species had intl gene. The isolated bacteria were sensitive to cefotaxime and ciprofloxacin (100\%). Also isolates were resistant to nalidixic acid, tetracycline and streptomycin. All isolate with class 1 integron were multidrug resistant.

Conclusions: The result of this study showed that due to increased level of drug resistance in S. infantis and the presence of class 1 integron in these strains, resistance can be transferred to other food borne pathogens.

Keywords:Salmonella; Class 1 Integron; Antibiotic Resistant; Salmonella Infantis

\section{Background}

Infection with non-typhoid Salmonella (NTS) spp is one of the most important health problems all over the world (1). In the last two decades, antibiotic-resistant Salmonella species have emerged originating from foodproducts (2). In many countries, Salmonella infantis has been reported as a cause of human salmonellosis among S. enterica serotypes (3-6). In Europe, S. enterica and S. typhimurium have been the third most common serotypes (1.1\%) followed by S. enteric. Furthermore, S. infantis strains isolated from the human and non-human resources have shown increased resistance to multiple drugs $(5,7)$. In many studies in Iran, the prevalence of Salmonella is shown to be increasing in both human and food-product samples $(8,9)$. Chicken is one of the main reservoirs for Salmonella in Iran (10).

Antimicrobial resistance of this pathogen may lead to the spread of virulence species. Multidrug resistance (MDR) Salmonella has become a major problem for the medical and veterinary communities in many countries including Iran (10-12). Factors contributing to resistance and virulence may be located on chromosomes, plasmids, transposons, integrons or phages $(13,14)$. Integrons are DNA elements that can transfer antibiotic resistance genes among bacteria (2). Class I integrons are the most common type of integrons recognized among the multidrug-resistant Salmonella (15). In recent years, various studies have been implemented in industrial countries in the field of antimicrobial resistance investigating integrons in food borne Salmonella $(14,16-19)$. But, information regarding the type and distribution of antimicrobial resistance-associated integrons among food transmitted pathogens is very limited in Iran.

Implication for health policy/practice/research/medical education:

Due to increased level of drug resistance in S. infantis and the presence of class 1 integron in these strains, resistance can be transferred to other food borne pathogens.

Copyright ( ) 2014, Ahvaz Jundishapur University of Medical Sciences; Published by Kowsar Corp. This is an open-access article distributed under the terms of the Creative Commons Attribution License, which permits unrestricted use, distribution, and reproduction in any medium, provided the original work is properly cited. 


\section{Objectives}

The aim of the present study was to find out the occurrence and frequency of multidrug resistance species and associated integron genes in Salmonella isolates from chicken in Iran.

\section{Materials and Methods}

\subsection{Bacterial Isolates}

\subsubsection{Sampling and Isolation of Salmonella}

This cross-sectional study was performed on 50 S. infantis isolated strains, collected from 135 chicken samples between 2009-2011. Serotyping of Salmonella spp, isolates was done by slide agglutination kits (Bio Merieux, France; DIFCO, USA) and compared with KauffmannWhite scheme (20). Pure colonies of each isolate of Salmonella were collected in two sterile 1.5 micro tubes; in a way that one of them contained one $\mathrm{mL}$ distilled water and the other one $\mathrm{ml}$ physiological serum. These samples were kept in- $20^{\circ} \mathrm{C}$ for performing sensitivity test and DNA extraction.

\subsubsection{Antimicrobial Susceptibility Testing}

From 28 antibiotics commonly used in veterinary and medicine, 14 antibiotics were selected including Gentamicin ((GM: $10 \mu \mathrm{g})$, Trimethoprim-Sulfametoxasol (SXT: $5 \mu \mathrm{g})$, Nalidixic acid (NA: $30 \mu \mathrm{g}$ ), Ciprofloxacin (CRO: 30 $\mu \mathrm{g})$, Cefotaxime (CTX: $30 \mu \mathrm{g})$, Imipenem (IPM: $10 \mu \mathrm{g})$, Colistin (CL: $10 \mu \mathrm{g})$, Ceftazidime (CAZ: $30 \mu \mathrm{g})$, Amoxicillin (AMX: $30 \mu \mathrm{g}$ ), Ampicillin (Amp: $10 \mu \mathrm{g}$ ), Chloramphenicol (C:30 $\mu \mathrm{g}$ ), Streptomycin (S:10 $\mu \mathrm{g}$ ), and Tetracycline (TE: 30 $\mu \mathrm{g})$. The selected antibiotics were tested using two methods including disc diffusion (Kirby-Bauer) according to the recommendations of standard protocol of CLSI 2011 (21).

Minimum Inhibitory Concentrations (MIC) were determined by the micro dilution method in Mueller-Hinton broth and the MIC breakpoint levels and concentration ranges of each antimicrobial agent were as follows: 512$2048 \mu \mathrm{g} / \mathrm{mL}$ for Nalidixic acid; 8-64 $\mu \mathrm{g} / \mathrm{mL}$ for Tetracycline; $64->1024 \mu \mathrm{g} / \mathrm{mL}$ for Streptomycin; 8-256 $\mu \mathrm{g} / \mathrm{mL}$ for Chloramphenicol; 512-> $2048 \mu \mathrm{g} / \mathrm{mL}$ for Trimethoprim and $0.01-8 \mu \mathrm{g} / \mathrm{mL}$ for ceftazidime, according to the recommendations of the Clinical and Laboratory Standard Institute's (CLSI) guidelines (21). These antibiotics were purchased from Sigma Chemical Company.

\subsubsection{DNA Extraction}

For DNA extraction, the High Pure PCR Template Preparation Kit (Roche, Germany) was used. After extracting the DNA, each sample was kept in $-20^{\circ} \mathrm{C}$ until the PCR stage.

\subsection{Class 1 Integron PCR}

The primer sequences were as follows: $\mathrm{R}^{\prime}$-CCC GAG
GCA TAG ACT GTA-3` and F5-CAG TGG ACA TAA GCC TGT TC-3' for the amplification of intl gene, which would produce a 164 base pair product. The PCR reaction was performed in final volume of $50 \mu \mathrm{L}$ which contained $10 \mu \mathrm{L}$ extracted DNA (equal to $1 \mu \mathrm{g}$ ), $5 \mathrm{pmol} / \mathrm{L}$ from each primer, $1.5 \mathrm{mmol} / \mathrm{L} \mathrm{MgCl}_{2}, 0.2 \mathrm{mmol} / \mathrm{L}$ dNTPs, and 1.5 unit of Taq enzyme $(22,23)$. The amplification reaction for int1 gene included primary denaturation at $94^{\circ} \mathrm{C}$ for 4 minutes and then, was followed by 35 cycles of denaturation at $94^{\circ} \mathrm{C}$ for 30 seconds, annealing at $55^{\circ} \mathrm{C}$ for 30 seconds, and extending at $72^{\circ} \mathrm{C}$ for 30 seconds. Moreover one cycle of the final extension at $72^{\circ} \mathrm{C}$ for five minutes was performed (8). PCR reaction was conducted in the presence of positive and negative controls. After performing PCR reaction, electrophoresis of PCR products was conducted in $1.5 \%$ agarose gel for 60 minutes. The gel was stained with $2 \mu \mathrm{g} / \mathrm{mL}$ ethidium bromide. Then, the results were evaluated under UV light on the UV gel document system. After PCR, the specific band with correct size was considered as a fragment of intl gene.

\subsection{Statistical Analysis}

The data was analyzed using the SPSS statistical software version 18. The Chi-square test was employed to calculate the P values in terms of number of antibiotic resistant integron positive and negative isolates. The $\chi^{2}$ test, or the Fishers' exact test, when appropriate, was used in a univariate analysis to assess the differences between two groups of isolates. P values less than 0.05 were considered as statistically significant.

\section{Results}

The isolated bacteria were sensitive to cefotaxime and ciprofloxacin (100\%). Also, all isolates were resistant to nalidixic acid, tetracycline and streptomycin. Furthermore, twenty-three multi-drug resistance patterns were demonstrated and indicated that $16 \%(n=8)$ and $12 \%(n$ $=6$ ) of these isolates were resistant to at least four and nine antimicrobial agents, respectively. The most common phenotypic patterns were related to six antibiotics (34\%). Moreover, $\mathrm{MIC}_{90}$ and $\mathrm{MIC}_{50}$ values were evaluated for the six antibiotics with the highest resistance rate for all isolates. These results indicated that all isolates were resistant to nalidixic acid and trimethoprim (MIC > 2048 $\mu \mathrm{g} / \mathrm{L}), 94 \%$ were resistant to tetracycline $(\mathrm{MIC}=64 \mu \mathrm{g} / \mathrm{L})$, $86 \%$ were resistant to streptomycin (MIC $=1024 \mu \mathrm{g} / \mathrm{L}$ ), $72 \%$ were resistant to chloramphenicol (MIC $=256 \mu \mathrm{g} / \mathrm{L})$ and $20 \%$ were resistant to ceftazidime (MIC $=8 \mu \mathrm{g} / \mathrm{L}$ ) (Table 1 ).

Furthermore, PCR analysis was performed for all isolates and class I integron gene was detected in 18 out of 50 strains (36\%) (Figure 1). Distribution of class I integron gene in association with the disc diffusion susceptibility tests are shown in Table 2. These findings demonstrated that $100 \%$ of integron-positive strains were resistant to nalidixic acid, tetracycline and streptomycin. No significant relation was e seen between the presence of integron gene and the resistance to the antibiotics. In 
Table 1. Comparison of the Degree of Sensitivity and Resistance Rate of S. infantis by two Methods of Disk Diffusion and Micro Dilution Tube ${ }^{a, b}$

\begin{tabular}{|c|c|c|c|c|c|c|}
\hline \multirow[t]{2}{*}{ Antimicrobial Agent } & \multicolumn{3}{|c|}{ MIC, $\mu \mathrm{g} / \mathbf{m L}$} & \multirow{2}{*}{$\begin{array}{c}\text { MIC, \% } \\
\mathbf{R}(\mathbf{N}) \\
\end{array}$} & \multirow{2}{*}{$\begin{array}{l}\mathrm{DD}, \% \\
\mathbf{R}(\mathbf{N}) \\
\end{array}$} & \multirow[t]{2}{*}{ P Value } \\
\hline & Range & MIC $_{50}$ & MIC $_{90}$ & & & \\
\hline Nalidixic acid & $512-2048$ & 614 & 2048 & $100(50)$ & $100(50)$ & NS \\
\hline Tetracycline & $8-64$ & 16 & 32 & $94(47)$ & $100(50)$ & NS \\
\hline Streptomycin & $64->1024$ & 512 & 1024 & $86(43)$ & $100(50)$ & 0.0012 \\
\hline Chloramphenicol & $8-256$ & 64 & 128 & $72(36)$ & $64(32)$ & NS \\
\hline Trimethoprim & $512->2048$ & 2048 & $>2048$ & $100(50)$ & $66(33)$ & $>0.001$ \\
\hline Ceftazidime & $0.01-8$ & 0.5 & 1 & $20(10)$ & $28(14)$ & NS \\
\hline
\end{tabular}

a Abbreviations: DD, Method of Disk Diffusion; MIC, Minimum Inhibitory Concentrations Method; MIC50, minimal concentration, inhibits 50\% of analyzed strains; MIC90, minimal concentration, inhibits $90 \%$ of analyzed strains; NS, not significant.

b Data are presented in No. (\%).

Table 2. Frequency Distribution of Class I Integron Gene in S. Infantis Based on Disc Diffusion Results a, b

\begin{tabular}{lcccc}
\hline antimicrobial Agent & Disc Diffusion $(\mathbf{n}=\mathbf{5 0})$ & Integron Negative $(\mathbf{n}=\mathbf{3 2})$ & Integron Positive $(\mathbf{n}=\mathbf{1 8})$ & P Value \\
\hline Nalidixic acid & $100(50)$ & $100(32)$ & $100(18)$ & NS \\
Tetracycline & $100(50)$ & $100(32)$ & $100(18)$ & NS \\
Streptomycin & $100(50)$ & $100(32)$ & $100(18)$ & NS \\
Amoxicillin & $70(35)$ & $78.1(25)$ & $55.6(10)$ & NS \\
Chloramphenicol & $64(32)$ & $65.7(21)$ & $61.1(11)$ & NS \\
Trimethoprim & $66(33)$ & $72(22)$ & $61.1(11)$ & NS \\
Amoxi-Clavulanic acid & $32(16)$ & $40.6(13)$ & $22.3(3)$ & NS \\
Ceftazidime & $28(14)$ & $12.5(4)$ & $50(10)$ & 0.009 \\
Colistin & $24(12)$ & $25(8)$ & $12.5(4)$ & NS \\
Ampicillin & $10(5)$ & $6.2(2)$ & $16.6(3)$ & NS \\
Gentamicin & $2(1)$ & $3.1(1)$ & $0(0)$ & NS \\
Imipenem & $0(0)$ & $0(0)$ & $0(0)$ & NS \\
Cefotaxime & $0(0)$ & $0(0)$ & $0(0)$ & NS \\
Ciprofloxacin & $0(0)$ & $0(0)$ & $0(0)$ & NS \\
\hline D & & & & \\
\hline
\end{tabular}

a Data are presented in No.(\%).

b $\mathrm{P}<0.05$ was considered significant.

Figure 1. Gel-Electrophoresis of the PCR Products of the Examined S. infantis Strains

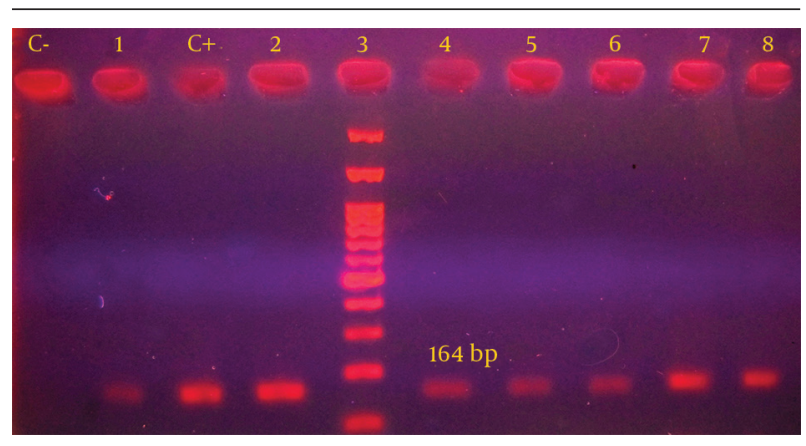

DNA size marker=100 bp; C-, negative control; C+, positive control of Int-1; lane 1-3, examined strains. addition, the findings obtained from the current study indicated that all isolates with multi drug resistant patterns had class I integron gene.

\section{Discussion}

Although integron class 1 plays an important role in creating and transferring the antibiotics resistance and its wide prevalence is alarming for infections caused by this bacterium (24). The results of the present study demonstrated that 18 strains of S. infantis (36\%) contained class I integron. In other studies, the frequency of class I integron was reported to be $11-66 \%$ among different human and animal sources (16). The use of antimicrobial compounds in animal food increase the rate and spreading of antimicrobial resistance among Salmonella strains (25). During recent decades, different serotypes of Salmonella 
have become increasingly resistant to common antibiotics, and the appearance of multi resistance to effective antibiotics in clinic has become a health concern for health authorities in developing countries (2).

According to several studies from Iran, the incidence of infection and multi-drug resistance to $S$. infantis is increasing in human and foods $(8,9)$. Drug susceptibility testing in S. infantis strains showed that $100 \%$ were sensitive to nalidixic acid, tetracycline and streptomycin. Several studies have been performed in Iran, showing high frequency of resistance to ciprofloxacin and nalidixic acid for S. enterica and S. infantis $(10,26)$. Resistance to these antibiotics has been reported in many studies in other countries $(27,28)$; however, resistance rate in our study was considerably higher in comparison with other studies. In the Nogrady et al. investigation, resistance to nalidixic acid was reported to be at MIC $\geq 256 \mu \mathrm{g} / \mathrm{L}$ while it was at MIC $>2048 \mu \mathrm{g} / \mathrm{L}$ in the present study (6). Also our findings indicate that $16 \%$ of strains were resistant to at least four, and $12 \%$ to nine antibiotics.

In the studied strains, 22 antibiotic resistance patterns were observed and the most common anti-biotypes (34\%) were associated with the phenotype of resistance to six antibiotics. In a study by Dahshan et al. on S. infantis strains, resistance pattern was reported to be to AMP, CHI, STR, SUL, TE, CEF, FOX and CAZ (28). The reason for increasing resistance among species that can cause food infection is indiscriminate and uncontrolled use of antibiotics for medical and veterinary purposes which causes destruction of sensitive bacteria and selection of resistant strains to several antibiotics. These strains can directly infect human through food consumption and can transfer resistance genes to human endogenous flora (29). Restriction in the use of antibiotics in animals and humans, antibiotics sensitivity testing for the selection of appropriate drug (s), and observing the dose of medications and treatment duration can decrease the number of resistant strains.

Up until now, more than 80 resistance genes have been identified for class I integrons which confer the resistance of the bacteria to different antibiotics. Our findings revealed that $100 \%$ of integron-positive strains were resistant to nalidixic acid, tetracycline and streptomycin. But other than that, except for ceftazidime, no significant association was observed between the presence of class I integron gene and antimicrobial resistance. The association of resistance gene and class I integrons in S. infantis has been described in several studies $(10,30,31)$. In a study by Naghoni et al. conducted on clinical (samples), $96 \%$ of integron-positive samples were resistant to tetracycline and $83 \%$ to streptomycin (8). In another study by Japanese researchers, resistance to streptomycin and tetracycline in S. infantis isolated from chicken was associated with the presence of class I integron $(32,33)$.

Different resistance genes have been identified in S. infantis (34). These observations indicate the relationship between the size and the source of class I integrons and efflux proteins encoding resistance genes in this bacteria (28). Although transmission of resistance in Salmonella infections is complex and not exactly clear, most resistant Salmonella infections result from contaminated food of animal origin (6). These resistant bacteria in foods are considered as a threat for human's health; and therefore, it is recommended that antibiotic resistance genotypes and their association with class I integrons be evaluated in the strains resistance to multiple antibiotics.

In our study, the rate of antibiotic resistance has been high among $S$. infantis strains and a great number of these isolates have been found with multi-antibiotic resistance. Monitoring and surveillance of antimicrobial resistance including integron screening as an indicator of resistance acquisition can be an important strategy to combat antibacterial resistance among these microorganisms.

\section{Acknowledgements}

We thank the research council of Babol University of Medical Sciences for the financial support.

\section{Authors' Contribution}

The authors declare no financial disclosure to report.

\section{Financial Disclosure}

None declared.

\section{Funding/Support}

This work was supported by a grant from Babol University of Medical Sciences, Babol, IR Iran.

\section{References}

1. Parry CM, Threlfall EJ. Antimicrobial resistance in typhoidal and nontyphoidal salmonellae. Curr Opin Infect Dis. 2008;21(5):531-8.

2. Wannaprasat W, Padungtod P, Chuanchuen R. Class 1 integrons and virulence genes in Salmonella enterica isolates from pork and humans. Int J Antimicrob Agents. 2011;37(5):457-61.

3. Ishihara K, Takahashi T, Morioka A, Kojima A, Kijima M, Asai T, et al. National surveillance of Salmonella enterica in food-producing animals in Japan. Acta Vet Scand. 2009;51:35.

4. Merino LA, Ronconi MC, Navia MM, Ruiz J, Sierra JM, Cech NB, et al. Analysis of the clonal relationship among clinical isolates of Salmonella enterica serovar Infantis by different typing methods. Rev Inst Med Trop Sao Paulo. 2003;45(3):119-23.

5. Dionisi AM, Lucarelli C, Benedetti I, Owczarek S, Luzzi I. Molecular characterisation of multidrug-resistant Salmonella enterica serotype Infantis from humans, animals and the environment in Italy. Int J Antimicrob Agents. 2011;38(5):384-9.

6. Nogrady N, Toth A, Kostyak A, Paszti J, Nagy B. Emergence of multidrug-resistant clones of Salmonella Infantis in broiler chickens and humans in Hungary. JAntimicrob Chemother. 2007;60(3):6458.

7. Busani L, Graziani C, Battisti A, Franco A, Ricci A, Vio D, et al. Antibiotic resistance in Salmonella enterica serotypes Typhimurium, Enteritidis and Infantis from human infections, foodstuffs and farm animals in Italy. Epidemiol Infect. 2004;132(2):245-51.

8. Naghoni A, Ranjbar R, Tabaraie B, Farshad S, Owlia P, Safiri Z, et al. High prevalence of integron-mediated resistance in clinical isolates of Salmonella enterica.Jpn J Infect Dis. 2010;63(6):417-21.

9. Chashni SHE, Hassanzadeh M, Fard MHB, Mirzaie S. Characteriza- 


\section{Asgharpour F et al.}

tion of the Salmonella isolates from backyard chickens in north of Iran, by serotyping, multiplex PCR and antibiotic resistance analysis. Arch Razi Inst. 2009;64(2):77-83.

10. Rahmani M, Peighambari SM, Svendsen CA, Cavaco LM, Agerso Y, Hendriksen RS. Molecular clonality and antimicrobial resistance in Salmonella enterica serovars Enteritidis and Infantis from broilers in three Northern regions of Iran. BMC Vet Res. 2013;9:66.

11. Ashtiani MT, Monajemzadeh M, Kashi L. Trends in antimicrobia resistance of fecal Shigella and Salmonella isolates in Tehran, Iran. Indian J Pathol Microbiol. 2009;52(1):52-5.

12. Hamidian M, Tajbakhsh M, Walther-Rasmussen J, Zali MR Emergence of extended-spectrum beta-lactamases in clinical isolates of Salmonella enterica in Tehran, Iran. Jpn J Infect Dis. 2009;62(5):368-71.

13. Rychlik I, Gregorova D, Hradecka H. Distribution and function of plasmids in Salmonella enterica. Vet Microbiol. 2006;112(1):1-10.

14. Khan AA, Ponce E, Nawaz MS, Cheng CM, Khan JA, West CS. Identification and characterization of Class 1 integron resistance gene cassettes among Salmonella strains isolated from imported seafood. Appl Environ Microbiol. 2009;75(4):1192-6.

15. Chu C, Chiu CH. Evolution of the virulence plasmids of non-typhoid Salmonella and its association with antimicrobial resistance. Microbes Infect. 2006;8(7):1931-6.

16. Molla B, Miko A, Pries K, Hildebrandt G, Kleer J, Schroeter A, et al. Class 1 integrons and resistance gene cassettes among multidrug resistant Salmonella serovars isolated from slaughter animals and foods of animal origin in Ethiopia. Acta Trop. 2007;103(2):142-9.

17. Zhao S, Fedorka-Cray PJ, Friedman S, McDermott PF, Walker RD, Qaiyumi S, et al. Characterization of Salmonella Typhimurium of animal origin obtained from the National Antimicrobial Resistance Monitoring System. Foodborne Pathog Dis. 2005;2(2):169-81.

18. Miko A, Pries K, Schroeter A, Helmuth R. Molecular mechanism of resistance in multidrug-resistant serovars of Salmonella enterica isolated from foods in Germany. J Antimicrob Chemother. 2005;56(6):1025-33.

19. Vo AT, van Duijkeren E, Gaastra W, Fluit AC. Antimicrobial resistance, class 1 integrons, and genomic island 1 in Salmonella isolates from Vietnam. PLoS One. 2010;5(2).

20. Bale JAd, Threllfall EJ, Ward LR. Kauffmann-White Scheme.London: Health Protection Agency, Colindale; 2007.

21. Wikler MA, Cockeril FR, Craig WA, Dudley MN, Hecht DW. Method for Dilution Antimicrobial Test for Bacteria that Grow Aerobically; Approved Standard. 8th ed: clinical and laboratory Standards Institute; 2009.

22. Koeleman JG, Stoof J, Van Der Bijl MW, Vandenbroucke-Grauls
CM, Savelkoul PH. Identification of epidemic strains of Acinetobacter baumannii by integrase gene PCR. J Clin Microbiol. 2001;39(1):8-13.

23. Ranjbar R, Giammanco GM, Farshad S, Owlia P, Aleo A, Mammina C. Serotypes, antibiotic resistance, and class 1 integrons in Salmonella isolates from pediatric cases of enteritis in Tehran, Iran. Foodborne Pathog Dis. 2011;8(4):547-53.

24. Rajabnia R, Asgharpour F, Ferdosi Shahandashti E, Khalilian M, Norkhomami S, Shafii M, et al. Class 1 Integron in Pseudomonas aeruginosa Isolates From Different Places and Devices of ICU in Babol, Iran.Jundishapur J Microbiol. 2013;6(2):138-43.

25. Antunes P, Machado J, Sousa JC, Peixe L. Dissemination amongst humans and food products of animal origin of a Salmonella typhimurium clone expressing an integron-borne OXA-30 betalactamase. J Antimicrob Chemother. 2004;54(2):429-34.

26. Morshed R, Peighambari SM. Drug resistance, plasmid profile and random amplified polymorphic DNA analysis of Iranian isolates of Salmonella enteritidis. New Microbiol. 2010;33(1):47-56.

27. Yan H, Li L, Alam MJ, Shinoda S, Miyoshi S, Shi L. Prevalence and antimicrobial resistance of Salmonella in retail foods in northern China. Int J Food Microbiol. 2010;143(3):230-4.

28. Dahshan H, Chuma T, Shahada F, Akiba M, Fujimoto H, Akasaka $\mathrm{K}$, et al. Characterization of antibiotic resistance and the emergence of AmpC-producing Salmonella Infantis from pigs. J Vet Med Sci. 2010;72(11):1437-42.

29. Benacer D, Thong KL, Watanabe H, Puthucheary SD. Characterization of drug resistant Salmonella enterica serotype Typhimurium by antibiograms, plasmids, integrons, resistance genes and PFGE. J Microbiol Biotechnol. 2010;20(6):1042-52.

30. Tajbakhsh M, Hendriksen RS, Nochi Z, Zali MR, Aarestrup FM, Garcia-Migura L. Antimicrobial resistance in Salmonella spp. recovered from patients admitted to six different hospitals in Tehran, Iran from 2007 to 2008. Folia Microbiol (Praha). 2012;57(2):91-7.

31. Fabrega A, Sanchez-Cespedes J, Soto S, Vila J. Quinolone resistance in the food chain. Int J Antimicrob Agents. 2008;31(4):307-15.

32. Shahada F, Chuma T, Tobata T, Okamoto K, Sueyoshi M, Takase K. Molecular epidemiology of antimicrobial resistance among Salmonella enterica serovar Infantis from poultry in Kagoshima, Japan. Int J Antimicrob Agents. 2006;28(4):302-7.

33. Kudaka J, Itokazu K, Taira K, Iwai A, Kondo M, Susa T, et al. Characterization of Salmonella isolated in Okinawa, Japan. Jpn JInfect Dis. 2006;59(1):15-9.

34. Shahada F, Sugiyama H, Chuma T, Sueyoshi M, Okamoto K. Genetic analysis of multi-drug resistance and the clonal dissemination of beta-lactam resistance in Salmonella Infantis isolated from broilers. Vet Microbiol. 2010;140(1-2):136-41. 